University of Nebraska - Lincoln

DigitalCommons@University of Nebraska - Lincoln

4-2021

\title{
Trends in content development and licensing of electronic resources
}

Christina Geuther

Casey D. Hoeve

Faye O'Reilly

Follow this and additional works at: https://digitalcommons.unl.edu/libraryscience

Part of the Library and Information Science Commons

This Article is brought to you for free and open access by the Libraries at University of Nebraska-Lincoln at DigitalCommons@University of Nebraska - Lincoln. It has been accepted for inclusion in Faculty Publications, UNL Libraries by an authorized administrator of DigitalCommons@University of Nebraska - Lincoln. 


\title{
Trends in content development and licensing of electronic resources
}

\author{
Christina Geuther, ${ }^{1}$ Casey D. Hoeve,${ }^{2}$ and Faye O’Reilly ${ }^{3}$
}

\author{
1 Kansas State University Libraries \\ 2 University of Nebraska-Lincoln Libraries \\ 3 Wichita State University Libraries \\ Contact - Faye O'Reilly, Wichita State University Libraries, \\ 1845 Fairmount, Wichita, KS 6726o, USA; faye.oreilly@wichita.edu \\ ORCID \\ Christina Geuther http://orcid.org/0000-0001-7538-5572 \\ Casey D. Hoeve http://orcid.org/0000-0003-4837-8910 \\ Faye O'Reilly http://orcid.org/o0oo-0003-4940-8181
}

\begin{abstract}
Academic libraries face the dual challenges of decreasing budgets and increasing demand for electronic resources. Librarians at three Midwestern US public research universities discuss the electronic resources environment, the direction of content development, and using future-proof as well as future-driven licensing language to best provide for the needs of today's library collections decisions. Trends are discussed in both content development areas and the negotiated license framework. This article offers pragmatic approaches to answer current questions for electronic resources librarians as they experience inflation increases and the greater Serials Crisis while still looking to build access to their digital investments.
\end{abstract}

Keywords: Collection development, content development, electronic resources, licensing; trends

Published in Journal of Electronic Resources Librarianship 2021, vol 33, no 1, pp 1-12. doi:10.1080/1941126X.2021.1871195

Copyright (c) 2021 Christina Geuther, Casey D. Hoeve, and Faye O’Reilly. Published by Taylor \& Francis Group, LLC. Used by permission. 


\section{Background of the serials crisis and content development trends}

As library content becomes increasingly digital, it requires a transition away from previous resource acquisitions paradigms, and invokes a need for the examination of emerging trends to address the needs of modern collection development. Key values of access, ownership, and preservation must be pragmatically managed within the boundaries of space, budgets, and licenses. As the landscape evolves, it is pivotal to understand these trajectories to holistically comprehend how libraries can successfully protect key values. Budgetary restrictions have been a prime concern, as annual inflation of resources continues to increase in an unsustainable manner. The additional weight of RCM budget model implementation can further affect libraries, who must justify value (Carrico, 2011), with the possibility for decreased revenue streams as a non-tuition-generating entity. Such practices cause libraries to spend a great deal of time on analyzing usage statistics, developing multiple budgetary scenarios, and engaging vendors in difficult negotiations. A lack of appropriate funding often results in an impasse (Price, 2020), subsequently forcing cancelations of big deal packages (Hoeve, 2019; SPARC, 2020a).

In an electronic environment of unsustainable collections, libraries must address post-cancelation rights that were initially sought and agreed to in prior licensing negotiations. Wading through a morass of split and repacked collections, interacting with vendors and subscription agents, and reading through the fine print of licenses, an abrupt halt in the subscription complicates library operations that are shortstaffed, and must handle catalog record updates of renewed and canceled journals. Some alleviation can occur at the consortia level by participating in "collective collections" partnerships, such as the Big Ten Academic Alliance (Dempsey et al., 2019); however, a spectrum from autonomy to collectivization still exists, and inchoate collective partnerships compel libraries to tackle these issues at the local level.

Modern practices in collection development continue to place licenses in transitional phases to accommodate and regulate vendor practices in the negotiation process. At the onset of reviewing resources for purchase, collection development librarians must clarify such services as (but not limited to):

- Availability and quality of MARC records 
- Provision of COUNTER usage statistics or a reliable equivalent

- Subscription access, evidence-based acquisition, demand driven acquisition, one time purchases, or "one-time purchases with hosting fees"

- Perpetual access at the point of purchase and cancelation; also, whether perpetual access and ownership are one in the same, or if fees are charged for access to perpetually owned content

- Public performance rights

- Accessibility and platform functionality, including usability and algorithm relevance

- Preservation systems in place, such as CLOCKSS, LOCKSS, Portico, or if content if provided by hard drive and expected to be hosted locally

- Cost, inflation percentage and predicted budget forecasting in a Serials Crisis state (SPARC, 202Ob)

These factors extend beyond traditional analysis of integrated library systems reports, and place additional burdens as emerging analytical resources are often run in tandem. Collection mapping tools, such as GreenGlass or Gold Rush require permissions to share and manipulate data in tripartite agreements between library, vendor, and comparator institutions. Purchasing data for analysis can be negotiated on the local level, or completed at the consortial level. The Big Ten Academic Alliance has partnered with Clarivate to purchase Web of Science and store it for analytics in the Collaborative Archives \& Data Research Environment (CADRE)-an "IMLS-funded project that provides sustainable, affordable, and standardized text- and data-mining services for licensed big datasets, as well as open and non-consumptive datasets, too large or unwieldy to work with in existing research library environments" (CADRE, 2020).

Furthermore, collection development is exploring adjusted costs for journals packages with open access content. Multiple technologies and platforms allow for deep level analysis, such as UnSub, ROAM. plus, Delta Think, and Wiley Open Access Dashboard. These emerging areas effectively question the ownership of content and data, and are leading toward a licensing trajectory of transformative agreements, which aim to offset the costs incurred by university-funded research. 


\section{Current licensing needs based on best practices for content development}

There are two major phenomena that cause today's emerging license language. The first is content development calling for increased user access; the second is license language that is a reaction to budgetary constraints. These phenomena have quickly evolved into a set of recognizable best practices for library collections, and licensing professionals are still catching up. In fact, much of the formula is led by model licenses or a sprinkling of literature written with a sense of urgency. It says first the critical situation, then the theory. Has the Serials Crisis caused librarians to be more reactionary than proactive?

The authors of this article intend to encourage the field to move toward the latter by preparing institutions to take necessary steps forward to modernize electronic resources policies and procedures. For developments in negotiating user access, this section will describe: text and data mining; Voluntary Product Accessibility Tests (VPATs); accessibility; confidentiality of user data; and standards for usage statistics including COUNTER and SUSHI. The second half of this section will discuss precautionary language for libraries facing budget constraints, including: non-disclosure agreements; termination rights due to lack of funding appropriation; title cancelations and transfers; notice of cancelation period; and perpetual access language considerate of present and future local needs.

\section{Text and data mining}

In Williams et al.'s case study at University of Colorado (2014), medical researchers required "a large collection of full-text journals in $\mathrm{XML}$, the right to text mine the collection, and the right to store and use the collection and the data mined from it for grant-funded research." (6) Some mining involves systematically downloading articles and converting them to XML. This process of conversion, changing the state of the material, may be a breach in itself. However, it would be wise to include this change of state within the terms of a TDM license. It also creates a standard practice that can model. Another point to note is that the research team in this study was the only party listed as authorized users. Previous attempts at making 
TDM a generally negotiated term have looked at LIBLICENSE's model license. These terms are:

"Text and Data Mining. Authorized Users may use the Licensed Materials to perform and engage in text and/or data mining activities for academic research, scholarship, and other educational purposes, utilize and share the results of text and/or data mining in their scholarly work, and make the results available for use by others, so long as the purpose is not to create a product for use by third parties that would substitute for the Licensed Materials. Licensor will cooperate with Licensee and Authorized Users as reasonably necessary in making the Licensed Materials available in a manner and form most useful to the Authorized User. If Licensee or Authorized Users request the Licensor to deliver or otherwise prepare copies of the Licensed Materials for text and data mining purposes, any fees charged by Licensor shall be solely for preparing and delivering such copies on a time and materials basis." (Liblicense Model License Agreement, 2014)

We suggest changing the "available in a manner and form most useful" to "XML." That would cut down a lot of the manual work by professors and graduate students, and be consistent with University of Colorado's treatment.

\section{VPATs}

Integrating VPATs into content development and electronic resource acquisitions workflows is one way to successfully protect key values and address patron needs while navigating the complexities of information vendor practices. VPATs will help libraries determine what the minimum level of conformance is-or establish a standard of accepted accessibility to compare all resources to-which can be accomplished via a usability study.

Inaccessible e-resources are a critical situation. In the last ten years, several academic libraries have found themselves in legal trouble due to the inaccessibility of their licensed content to users with 
impairments. Some of the more notable cases include the Universities of Montana and California, which resulted in the creation of checklists for evaluating the accessibility of e-resources, such as the Tatomir Accessibility Checklist (Tatomir \& Durrance, 2010). The success of these checklists lies in the librarian's understanding of what makes resources accessible. Section 508 guidelines require the creation of VPATs, which can be a useful assessment and decision-making tool and help librarians establish a minimum level of conformance for their libraries.

The many checklists created to measure how accessible an e-resource is share the same core concepts, what would be considered minimal conformance. A checklist makes a usability study easier to manage, giving a list of features to check and test, but librarians should also have an understanding of, and access to the most basic of assistive technologies. Screen-reading software is critical to a usability study, as it is the best way to test if a resource will interact with other assistive technologies. Additionally, a checklist can be tailored to the type of resource being evaluated. For example, alternative text for images is more important in making a photography database accessible than it is in making a journal article database accessible. Special attention must be paid to navigation and compatibility with screen-reading software, as users with visual impairments, who struggle the most with online content, rely on these devices to interact with the e-resource.

As content creators, digital content vendors share equal responsibility for equitable access but do not shoulder the burden. Libraries have a responsibility to demand resources that are more accessible and have the tools to voice their concerns. Sustainability of VPAT reviews is a concern for libraries with smaller staffs, but the BTAA VPAT review is a list of popular academic resources for accessibility reviews, providing evaluations for a number of popular electronic resources licensed by libraries. A quick look at the results of the BTAA VPAT review is an excellent way to make a decision on whether or not a new e-resource meets your libraries' accessibility requirements.

Accessibility considerations, like a VPAT review in the e-resources acquisitions workflow, modernizes e-resources policies and procedures. Usability results inform the collection decision thereby creating more accessible collections in the next ten years than libraries 
have had in the last ten years. Libraries committing to license only accessible resources updates collection policies that have not considered the information needs of users with impairments. With decreasing budgets and increasing acquisition costs of necessary resources for programs at academic institutions, it can be more and more difficult to make decisions about what should stay and what should go. Accessibility can tip the scale and allow libraries explore possibilities for alternative resources that are more accessible and justify cancelations. Unfortunately, there may be a lack of alternatives for niche e-resources.

\section{Accessibility}

Libraries have legal and ethical obligations to provide equitable access to resources but face a barrier to that access as much of the licensed content resides on platforms built and maintained by content providers. Libraries do not have the ability to change content delivery systems, aside from run-of-the-mill customization. However, eresource licensing can open the door to effecting change and holding publishers accountable for not only the quality of content, but also the accessibility of content. Vendors cannot continue to put usability on the backburner, nor can libraries be complacent with the lack of accessible resources, especially when the burden of providing access to accessible resources and the legal consequences of not providing equitable access falls on libraries alone. Additionally the burden of making resources accessible falls on the user with impairments. Libraries can start by committing to accessibility in licensing. At present, the Big Ten Academic Alliance (BTAA) and the Association of Southeastern Research Libraries (ASERL) are partnering to "advance equal access to information through evaluation of resources, and publicly posting evaluations for review by vendors and libraries" (Armstrong \& Burger, 2019). Providing access to information is embedded within libraries' core values which have not changed in the last one hundred years. The future of libraries' values is inclusive. Accessibility and inclusivity are key values in access.

Accessibility of resources should be considered in the decision-making process. Librarians may need to seek out alternative resources or expect to rely on accommodations at the university level. 
In terms of licensing, the aforementioned BTAA and ASERL partnership has provided guidance on including language regarding digital accessibility. But licensing language is only a step in the right direction. An understanding of what makes resources accessible is crucial to continue to bring the discussion of accessible platforms to content providers, as well as to safeguard the access values of librarianship. Continuous usability studies are needed to determine whether resources fit the accessibility guidelines for your institution.

Eventually a third phenomenon may arise in today's emerging licensing language: calling for a certain level of compliance with Section 508 standards. A level of conformance is implied by Section 508 as law, but rarely enforced until it's too late (lawsuit). The burden of access should not be placed on a user with impairments. Accessibility retains a sense of urgency, because of how little control libraries have over platforms and how accountable they are for noncompliance with disability law requirements, which is a critical situation. Where libraries have been reactionary about accessibility in the past, taking steps to integrate accessibility into collection development and licensing can help libraries be proactive with inclusivity in the future.

\section{Confidentiality of user data}

Sometime between 2005 and 2011, libraries transitioned from promoting implementation of technology to simply keeping up with technology. Unfortunately, in the race to keeping pace with planned obsolescence and consistent innovation, libraries have also transitioned into a dangerous practice of not keeping up with the downsides of technology, or rather not considering how that technology may infringe on patron privacy. Libraries are signing contracts with vendors without fully understanding the risks posed to the privacy of their patrons, with thousands of libraries unknowingly violating their own too broad privacy policies. Equally unfortunate is the lack of best practices in the literature to help libraries interpret and contend with information vendor's data policies, beyond ALA's library privacy guidelines (Gressel, 2014).

Librarians know better than others the cost of information, in terms of the price of licensing an e-resource, but what about the additional, hidden cost of user data? That data can be used by libraries 
to measure use and impact, and used by the platform to help enrich a user's search. However, the way patrons access and interact with these resources often gives access to extensive personal information about the users, which then becomes the property of whatever party is collecting the data. Property can be bought or sold, which means the user enters a hidden contract with the vendor that in exchange for searching a database for research articles or downloading an ebook, the user gives up private details about themself. This hidden contract is facilitated by the library without knowledge to the user or the libraries, which is alarming because libraries have always been bastions of privacy.

Because libraries rely on contracts with content vendors and delivery system vendors to provide access to and deliver digital content, perhaps companies the library has no direct relationship with (like Adobe), these contracts must be reviewed and negotiated to determine whether a vendor is as committed to protecting patrons' privacy as the library. Because there is money in the ad revenue generated by user data, vendors are often not on the same page as libraries when it comes to privacy.

The industry standard is free flowing information. Now more than ever, websites rely on cookies (small pieces of data created by the web browser that contain user information) but they come in many different flavors, many types posing a variety of privacy concerns. Privacy concerns should be at the forefront of library practices in a world of massive data breaches and identity theft. Most users do not know what cookies are and how they can be used and therefore may blindly agree to store non-essential cookies on their devices.

\section{COUNTER and SUSHI}

Data-driven decisions are becoming more routine, if not the archetypal method for determining resource renewals and cancelations; therefore, access to reliable and defined usage statistics are crucial for collection analysis. COUNTER reports are considered the gold standard by which libraries determine usage of resources. Complementing COUNTER is the SUSHI protocol, which is used to automatically send libraries COUNTER reports on a regular basis, whether through email or directly to an Integrated Library System (ILS) or an Electronic Resources Management System (ERM). 
While most information vendors provide COUNTER reports as a general service that is expected by libraries, some vendors do not have this provision written into a contract, or may not have the current capacity for providing COUNTER reports. It is crucial to ensure stipulations that vendors who can provide COUNTER reports adhere to the latest codes of practice, and send reports on a regular basis. It is also advisable to work with vendors who cannot provide COUNTER reports to commit to sending equivalent usage reports on agreed intervals. In certain circumstances, niche information providers may not know what Project COUNTER is, and this allows for conversations to inform vendors, and encourage them to adopt COUNTER, thereby helping to continually increase the standardization of usage statistics provision.

\section{Non-disclosure agreements in licenses}

Conventionally, deals have been made between vendors and libraries with the idea that keeping business terms confidential may lead to better deal-making. However, the conscience of solidarity among librarians across consortial institutions has many thinking that it would be better for the whole if terms were disclosed. Librarians may seek to share strategies for better deals this way, but this breaks the pattern upon which many vendors' sales staff had built their careers.

University of Nebraska-Lincoln follows the state requirement to disclose all licenses publicly, but redacting signatories. According to Nebraska Legislative Bill (LB) 429, and pursuant to Nebraska's Taxpayer Act (Neb. Rev. Stat. §84-602.01, as may be amended), as of January 1, 2014, the University of Nebraska is required to provide the Nebraska Department of Administrative Services with a copy of each contract that is a basis for an expenditure of state funds, including any amendments and documents incorporated by reference in the contract (these are published online by the state). In a more restrictive manner, Kansas State University and Wichita State University must respond to requests employing the Kansas Open Records Act, but that occurs on a case-by-case basis going through university general counsels. In these cases, note that NDA language in licensing is often written with the addition of the agreement that state policy will and must be followed by each signing party. 
Outside of tax policy, Cornell University Library (n.d.) publicly states its stance on not signing non-disclosure agreements. Their statement is a call to fairness, asserting that too often vendors had taken advantage of libraries through secret dealing. The question is, can the land grant institutions whose library policy on this issue may rely on state tax and public burden arguments, use their positions to help propagate Cornell's position? Can more fairness be had by libraries if they provided more visibility of the public right to disclosure? Can the cause go larger, as consortial parties work together to make a way out? Until there is broader disclosure of library and vendor negotiations, it is important for the licensing team at a library to incorporate a clause stating the appropriate public policy as a step forward.

\section{Termination due to lack of funding appropriation}

In today's environment of budget constraints, it is important to have a clause that protects a library if there is no way to pay the vendor for another year under contract. Some legal teams may argue that there is more value to a Termination of Convenience which may be enacted at any time by the licensee library. However, more commonly academic contracts may show the way out as a Termination Due to Lack of Funding Appropriation. The difference between how these two clauses are written is that, for Lack of Funding, the Licensor (Vendor) may request proof that bills cannot be paid, at which point the library would have to show that it could not pay any other vendor. Furthermore, according to library legal expert Tomas A. Lipinski (2013, 419), "If the licensee is bankrupt but has paid its annual renewal fee, the bankruptcy laws may again intervene through the automatic stay in which all transactions are frozen, turned, or rolled back to a point 90 days before the date the bankruptcy estate was created, if the bankruptcy filings were made with U.S. Bankruptcy Court.” One of the areas of confusion in termination of lack of funding appropriation clause use is how the claim is made: Is the institution as a whole or the library bankrupt? Who is responsible or authorized for making that claim on behalf of the licensee? Are all monies spent in order to make this claim or are some available to other vendors? Making those decisions is why crafting this language should be done at the local level. 
Again, Termination of Convenience would avoid these complications entirely; however it is more difficult for the other party to agree to this contractually.

\section{Transfer of titles (swaps), cancelations}

Titles often change without notice per year/on a different platform from vendor to vendor, and that may include which date of access is included. Vendors honor access dates on prior contracts, so it is important to refer to these changes within internal documentation. Librarians should also compare appendices within the license or, more commonly, the invoice, to reconcile and check each renewal in order to keep track of charges and changes (Walter \& Bird, 2006).

\section{Notice of cancelation period}

The two terms to know regarding a cancelation period are Explicit contracts and Auto-renewals. Explicit means that the license language is dated to apply within a specific beginning and end date; whereas an auto-renewal rolls the language into the next invoice cycle. For autorenewals, one must be aware of the cancelation period, or else the library is contractually obligated to pay the invoice and subscribe for another cycle. The amount of time contractually required for notice of termination is always negotiable. Ninety days appear far more generous to a vendor than thirty days, but it is simply more realistic of the timeline that is used by a library jobber and the timeline they use for processing and prepayment to the third-party vendor.

\section{Crafting perpetual access language to meet local current and future needs}

The legal analysis for librarianship provided by Tomas A. Lipinski (2013) equates the rights for Perpetual Access with different methods of archiving (399-403). Today's libraries seek digital archiving for ease of patron access. Even so, Perpetual Access clauses and Archiving clauses are treated separately on the Ex Libris Alma electronic resource license record interface. Some licenses will have both clauses. According to a survey by Bulock (Marshall \& Bulock, 2014, 73), “To 
add to the complexity, publishers will vary greatly in their perpetual access statements. Some simply state that perpetual access will be granted without further details, while other publishers include stipulations that they reserve the right to change the format of how they host access." Furthermore, Bulock's survey showed a majority of librarians interested in access to be provided by LOCKSS (Lots of Copies Keep Stuff Safe) or Portico (Marshall \& Bulock, 2014). LOCKSS members maintain a server of digital stacks that communicates with the vendor to crawl and ingest electronic journal content, preserving the look and feel of the content and publisher's branding in a dark archive (Ross \& Sutton, 2016). LOCKSS began in 1999 at Stanford University. Mering (2015) adds, "LOCKSS Boxes deliver content immediately whenever the publisher's website is unavailable for whatever reason" (261). Controlled LOCKSS (CLOCKSS) is a partnership between publishers and research libraries as a network of LOCKSS, with boxes controlled at Rice, Indiana, and Stanford Libraries rather than locally. Portico, also a dark archive, maintains the accessibility of the electronic content with the look and feel customized by the library at the time of purchase, and agrees to deliver the content through a webbased platform upon a trigger event (Ross \& Sutton, 2016). It is different from LOCKSS and CLOCKSS because it is a centralized preservation repository. According to Mering (2015), "Content is available to all Portico participants when a triggered event occurs, whether or not their institution had a license to the content" (262).

A growing problem Bulock (2014) found was tracking perpetual access. In his survey of major serials listservers ERIL-L and SERIALST, Bulock (2014) inquired participants their Carnegie classification and how they treated journals, books, and multimedia with regard to perpetual access. The survey found that most participants did not purchase perpetual access for multimedia and that this was a generally unfamiliar territory (Bulock, 2014). Most participants tracked perpetual access of journals, but not ebooks or multimedia; and the most popular method of tracking was the electronic resource management system (Bulock, 2014). Bulock notes, "Some participants struck a note of hopelessness, with one writing 'perpetual access in a contract means nothing'" (2014, 101). Building on this concern, Zhang and Eschenfelder (2011) studied the very clauses of model licenses against a sample of seventy-two North American library licenses in a longitudinal 
study from 2000 to 2009. The recommended term from model licenses most frequently appearing in the sample was automatic perpetual access upon termination of a subscription. The least frequent recommendation to appear was the inclusion of subscribed-to backfiles with perpetual access. The third major point to take away from this study is that the Zhang and Eschenfelder sample "showed no shared assumptions about where PA copies should be housed" (2011, 68).

\section{Making it happen: communicating collections values with organizational values}

Licensing teams may choose to create a policy, more commonly called license guidelines, in order to better communicate values internally and externally among negotiating parties. In the creation process for this framework, librarians combine the communication of collections values with organizational values. In other words, the process aligns acquisition goals with statements of mission. Bringing a sense of mission to the table also engages decision makers higher up. For example, in high-stakes, high-cost negotiations sometimes university librarians or deans may be involved with the proposal process between the parties in order to help voice the cause of librarians looking for the best option for the sought-after collection and user access.

Perhaps the most important aspect of policy is its presentation to the vendor. Is presentation of the mission by the presence of leadership enough? No. Presentation should also consider allocating time for give-and-take by the other party for full understanding. A current trend in policy awareness is to refer vendors to general library collections guidance on the library or consortial website. Preemptively com-

municating values like this conveys a more generalized acceptance of the terms by other vendors. It also provides the space for the vendor to read and approach the library with their own questions of need for the negotiation and how both parties may be better served. Foremost, it is fair and circumvents uneasy surprises during talks.

Policy ought to be visible to the local user/access provider community and vendors equally. Consider the parties at play representative of their stakeholders. In a negotiation, it is important for librarians to have consensus on their strategy; and not only the librarians at the table, but reaching out to public services as well. Academic librarians 
network with faculty and students in an intricate web, and the thread gets stronger with organizational values making an argument part of the mission of the whole. With more eyes on the substance of what goes into the negotiations, more insight can be offered to a resource's value to the collection or set of users. From that, better persuasion and better decisions contribute to the talks.

\section{Adapting sample language from model licenses}

Using sample language is a way to learn from lessons of peer institutions. It may be most helpful therefore to look for language from institutions that work with vendors in common with yours. The library may not be able to share confidential business terms such as bottomline numbers, but it can share the idea of the approach and general experience with license representatives or sales staff. For a public institution, it would be helpful to look for colleagues negotiating within your state contractual requirements.

First and foremost, when using a clause from another institution, the licensing librarian should tailor it to the circumstances within their own institution: identifying the correct titles/positions, governance and jurisdiction, as well as serving the future needs of their particular institution. For example, not every library shares the same approach for perpetual access or digital archiving. Please note that library consortia also provide licensing principles and guidelines for their members. There is a high level of diversity with which one may source language for one license's negotiation. Rather than providing one set of language to your negotiating team, offer up advantages of multiple sources. This prevents groupthink and offers a way to advance libraries forward with the best possible measures.

\section{When to go with gray language or opt for a more basic agreement}

There is a tendency for parties to add more descriptive language when negotiating, but the future of licensing may see more librarians opt for language that is quite the opposite. Language may come in the form of gray, vague description or be presented within a more basic structure. 
Silence may be used to advantage. If an item is not discussed in an agreement and it is within the auspices of Fair Use, there is no statement made by either party that it cannot be done, and thus no contractual obligation to regulate. Vague or absent description may also help to futureproof a document if it is not negotiated on a regular basis. For example, language naming a technological service or product may become obsolete. More importantly, the library may seek a more affordable technology in the future for something like perpetual access maintenance. In that case, the licensing librarian should negotiate to name the needs being met by the service now and how they might meet expectations in the future.

Librarians should continue to seek ideal language to meet the needs of today's digital environment but realize that vendor representatives may respond less readily to more complicated language requiring legal staff and more readily accept a simplified document.

The Shared Electronic Resources Understanding (SERU) is an agreement established by the National Information Standards Organization (more widely known as NISO) in 2008. Instead of requesting signatures of the parties, the vendor and libraries register online with NISO where this agreement is located. Some libraries may revise the terms of SERU by adding negotiated language on their invoices. However, such practice may cause confusion across subscribing parties especially if the licensing librarian is linking one SERU record to multiple items by different vendors for the sake of consistency (Geuther \& Greene, 2017). Therefore, the SERU agreement should be maintained in its published form. As it is presented by NISO, SERU has optimal language for electronic resources as a long-term and accessible perpetual investment. It is a basic document, easy to interpret, and may also expedite acquisitions with vendors who have few legal staff. According to a 2019 study on use of SERU in US libraries (Carter, 2019, 190), these terms are usually agreed upon in an average of 5.4 days and account for 2.5 agreements negotiated a year by the libraries surveyed. A conventional license may take weeks or months to negotiate in its entirety.

Another way that vendor legal teams are expediting negotiations with a more basic approach is using a master document. While this is a recent development, it adds more work for the electronic resources librarian. Little to no customizations are made to the master document, 
so electronic resources librarians are forced to evolve their filing practices. The language that is requested to add or negotiate is on a supplemental document, as some librarians have long practiced with SERU. The parties can best adapt by placing this language on the invoice (like SERU) and file the invoice record with the master license as one would an addendum. If title lists are separate from the main document, such as on a spreadsheet, they should be stored in archival format referencing the date of the license and invoice. Ideally, a vendor could modify the invoice with the title list.

\section{Future needs in content development and licensing literature}

\section{Transformative agreements}

Transformative Agreements on many levels are nascent, but making important strides in their capacity to help libraries create sustainable pricing models coupled with open access for institutional publications. In many cases transformative agreements attempt to offset costs, by reducing subscription prices from vendors by a specified amount per article for scholars publishing in their journals, and making those articles open access. Two of the most recognized models are Publish \& Read and Read \& Publish. Publish and Read allows libraries to pay the equivalent of Article Processing Charges (APCs) for each institutional publication, but with no additional costs to read the journal. Read and Publish contains subscriptions costs plus a one-time negotiated extra fee in the contract to make institutional publication open access (Hinchliffe, 2019).

Most recently, The MIT Framework for Publisher Contracts is a reworked transformative agreement with goals of "protecting scholar's publishing rights and reuse options, making works open access immediately, providing unrestricted computational analysis, reliable vendor preservation, and transparent and sustainable pricing" (MIT Libraries, 2019). Similarly, cOALition S in Europe has enacted Plan S, which requires all scholarly publications funded by public or private funding to be published in open access journals by 2021. However, these stipulations have eased to allow publishing in non-open access journals if the funding agency overrides that requirement (Van Noorden, 
2020). While aspirational in nature (Hoeve 2019, Hoeve \& Mering 2021), these frameworks provide templates for libraries to add language that seeks to regain control of institutionally- published content.

Future negotiations require that libraries engage with vendors to agree to contract terms that are sustainable. Transformative agreements still contain many shortcomings, often deviating from their initial goals of cost-neutral agreements and absorbing the exorbitant fees of Article Processing Charges (APCs) (Sall \& Tovstiadi, 2020). Capping APCs has not been universally explored, and could present increasingly unsustainable costs, similar to the situation that led to serials crises. It has not yet been determined if these agreements are sustainable to both libraries and information vendors, or if alterations will be made, akin to vendors' transition from Demand Driven Acquisitions to short-term loans and Evidence-Based Acquisitions programs. As models shift, libraries should be aware of such possible changes among others that will inevitably develop, and challenge sustainable business models for collections budgets.

\section{Non-negotiable master licenses}

Complicating these developments in negotiating is the document structure itself. Kansas State University's licensing team recognized a handful of recent licenses by big vendors moving into the formula of a non-negotiable master license that can be modified only on the invoice. Looking back, SERU was crafted with the idea in mind to negotiate on the invoice as well. Whether this was the thought behind the new structure is questionable. Static licenses or click-wrap licenses may be formatted by the parties by including a signature line and additional clauses if the vendor agrees; however the biggest issue with this method is that if the license was static to begin with, then how can it be confirmed that the vendor's larger office network expects to have the file retrieval in place for long-term sales relationships on a caseby-case basis like this. It simply is not reliable. Therefore, librarians are forced to respond with new processes for referral and discovery of their invoices. They have been doing this so far with title lists that more commonly appear on invoices than the boiler plate and addenda, so perhaps the shift is not far off from happening. 


\section{Conclusion}

Many of the examined trends in collection development that play out in licensing demonstrate a reaction to budgetary constraints. The entrance of new technology and concerns for accessibility are concurrent with new economic hardships. How can libraries meet their internal and external stakeholders' demand with the most sustainable solutions? Licenses are contracts written for interpretation over the life cycle of an electronic resource and its possible access in perpetuity. Therefore, the language of licenses ought to reflect a more sustainable mindset. It is the authors' hope that the examples and suggestions given in this article will provide a successful means forward for policy writers and negotiators advocating for the best future of librarianship.

Moving forward, a multifaceted approach to academic librarian education is needed within the peculiarities of state law around monies, federal laws of accessibility, land-grant mission where applicable, and sustainable librarianship. Getting down to business, one has to think outside the box when handling the funds of a university service that is not income-driven and in an environment where universities are facing budget insecurities. This pressure is already on the shoulders of every member of the collections team at the negotiating table.

Further, this awareness must be brought to the attention of every vendor, and can be through thoughtful strategy and solidarity across the libraries' network. The trends mentioned in this article are moving quickly, in some cases faster than the supporting literature, and require all hands on deck to craft manageable language and processes for the lifecycle of electronic resources. Thankfully, Wichita State, Kansas State, and University of Nebraska at Lincoln's consortia including the Big Ten Academic Alliance and Greater Western Library Alliance (GWLA) are responding to the call by making their policy visible on LISTSERVs to membership and outside librarians perusing their websites for strategies; and consequently taking a public stand for all libraries that negotiate with the same vendors. 


\section{References}

Armstrong, K., \& Burger, J. (2019). BTAA and ASERL announce library accessibility partnership. Retrieved August 06, 2020, from https:// www.btaa.org/about/news-and-publications/news/2019/08/01/ btaa-and-aserl-announce-library-accessibility-partnership

Bulock, C. (2014). Tracking perpetual access: A survey of librarian practices. Serials Review, 40(2), 97-104. https://doi.org/10.1080/00987913.2014.923369

CADRE. (2020). Indiana University Network Science Institute. Retrieved January 29, 2021, from https://iuni.iu.edu/resources/datasets/cadre

Carrico, S. (2011). An academic library's efforts to justify materials budget expenditures. Proceedings of the Charleston Library Conference. https://doi. org/10.5703/1288284314931

Carter, S. J. (2019, October). Adoption of NISO's Shared Electronic Resource Understanding (SERU) at US Academic Libraries. UMN Conservancy. Retrieved March 3, 2020, from https://conservancy.umn.edu/bitstream/ handle/11299/208699/6870-19705-1-PB.pdf? sequence $=1$

Cornell University. (n.d.). Nondisclosure clauses. Cornell University Library's Position on Nondisclosure Clauses in Licenses. Retrieved August 5, 2020 from https://www.library.cornell.edu/about/policies/nondisclosure

Dempsey, L., Malpas, C., \& Sandler, M. (2019). Operationalizing the BIG Collective Collection: A Case Study of Consolidation vs Autonomy. OCLC Research. https://doi.org/10.25333/jbz3-jy57

Geuther, C., \& Greene, M. (2017). Creating a standard of practice for license alternatives. Charleston Conference Proceedings. K-Rex. Retrieved March 3, 2020, from https://krex.k-state.edu/dspace/bitstream/handle/2097/35600/ Geuther and Greene Charleston final paper.pdf? sequence $=1$

Gressel, M. (2014). Are libraries doing enough to safeguard their patrons' digital privacy? Serials Librarian. Retrieved August 03, 2020 from https://doi.org/10.1 080/0361526X.2014.939324

Hinchliffe, L. J. (2019). Transformative agreements: A primer. The Scholarly Kitchen. Retrieved August 03, 2020, from https://scholarlykitchen.sspnet. org/2019/04/23/transformative-agreements/

Hoeve, C. D. (2019). Resource management in a time of fiscal scarcity: Combining qualitative and quantitative assessment for journal package cancellations. The Serials Librarian, 75(1-4), 42-50. https://doi.org/10.1080/03615 26X.2019.1576571

Hoeve, C. D., \& Margaret Mering. (2021). In Lay Terms: A brief history to the future of Open Access. The Serials Librarian, 46(4), 300-304. https://doi.org/1 0.1080/00987913.2020.1850041

Liblicense Model License Agreement. (2014). Retrieved September 1, 2019, from http://liblicense.crl.edu/licensinginformation/model-license/

Lipinski, T. A. (2013). The Librarian's legal companion for licensing information sources and services. Neal- Schuman. 
Marshall, D., \& Bulock, C. (2014). You call that perpetual? Issues in perpetual access. The Serials Librarian, 67(1), 72-75. https://doi.org/10.1080/03615 26X.2014.899294

Mering, M. (2015). Preserving electronic scholarship for the future: An overview of LOCKSS, CLOCKSS, Portico, CHORUS, and the Keepers Registry. Serials Review, 41, 260-265.

MIT Framework for Publisher Contracts. (2019). MIT libraries. Retrieved August 3, 2020, from https://libraries.mit.edu/scholarly/publishing/framework/

Price, G. (2020). Members of University of North Carolina at Chapel Hill Community are asked to provide feedback on Elsevier Journal Titles; Elsevier is asking \$2.6 million to renew current journal package of 2000 titles. Retrieved March 9, 2020, from https://www.infodocket.com/2020/03/og/universityof-north-carolina-at-chapel-hill-as-elsevier-asks-for-2-6-million-for-currentjournal-package-of-2000-titles-members-of-community-asked-to-providefeedback-on-elsevier-titles/

Ross, S. V. T., \& Sutton, S. W. (2016). Guide to electronic resources management. Libraries Unlimited.

Sall, J., \& Tovstiadi, E. (2020, March 10). Transformative agreements and their headaches: New roles for librarians [Presentation]. ER\&L Conference.

SPARC. (2020a). Big deal knowledge base. Retrieved March 9, 2020, from https:// sparcopen.org/our-work/big-deal-knowledge-base/

SPARC. (2020b). Big deal cancellation tracking. Retrieved March 9, 2020, from https://sparcopen.org/our-work/big-deal-cancellation-tracking/

Tatomir, J., \& Durrance, J. C. (2010). Overcoming the information gap: Measuring the accessibility of library databases to adaptive technology users. Library Hi Tech, 28(4), 577-594. Retrieved August 3, 2020, from https://doi. org/10.1108/07378831011096240

Van Noorden, R. (2020). Open-access plan S to allow publishing in any journal. Nature. Retrieved August 3, 2020, from https://www.nature.com/articles/ d41586-020-02134-6

Waller, A., \& Bird, G. (2006). We own it. The Serials Librarian, 50(1-2), 179-196. https://doi.org/10.1300/J123v50no1_17

Williams, L. A., Fox, L. M., Roeder, C., \& Hunter, L. (2014, September). Negotiating a text mining license for faculty researchers. Information Technology and Libraries, 33(3), 5 .

Zhang, M., \& Eschenfelder, K. R. (2011). License analysis of e-journal perpetual access. The Journal of Academic Librarianship, 40(1), 62-69. https://doi. org/10.1016/j.acalib.2013.11.002 